\title{
Mapping SARS-CoV-2 antigenic relationships and serological responses
}

\author{
One sentence summary: \\ Antigenic Cartography of SARS-CoV-2 variants reveals amino acid substitutions governing immune escape and \\ immunodominance patterns.
}

\begin{abstract}
Authors:
Samuel H. Wilks ${ }^{1, *}$, Barbara Mühlemann ${ }^{2,3,{ }^{*}}$, Xiaoying Shen ${ }^{4,5,{ }^{*}}$, Sina Türeli ${ }^{1}$, Eric B. LeGresley ${ }^{1}$, Antonia Netzl ${ }^{1}$, Miguela A. Caniza $^{6}$, Jesus N. Chacaltana-Huarcaya ${ }^{7}$, Xiaoju Daniell ${ }^{4}$, Michael B. Datto ${ }^{8}$, Thomas N. Denny ${ }^{5}$, Christian Drosten ${ }^{2,3}$, Ron A. M. Fouchier ${ }^{9}$, Patricia J. Garcia ${ }^{10}$, Peter J. Halfmann ${ }^{11}$, Agatha Jassem ${ }^{12}$, Terry C. Jones ${ }^{1,2,3}$, Yoshihiro Kawaoka ${ }^{11,13,14}$, Florian Krammer $^{15,16}$, Charlene McDanal ${ }^{4}$, Rolando Pajon ${ }^{17}$, Viviana Simon ${ }^{15,16,18,19}$, Melissa Stockwell ${ }^{20}$, Haili Tang ${ }^{4}$, Harm van Bakel ${ }^{21}$, Richard Webby ${ }^{22}$, David C. Montefiori, ${ }^{4,5}$, , Derek J. Smith ${ }^{1, \#}$
\end{abstract}

\author{
Affiliations: \\ 1: Center for Pathogen Evolution, Department of Zoology, University of Cambridge, Cambridge, CB2 3EJ, UK \\ 2: Institute of Virology, Charité - Universitätsmedizin Berlin, corporate member of Freie Universität Berlin, Humboldt-Universität \\ zu Berlin, and Berlin Institute of Health, 10117 Berlin, Germany \\ 3: German Centre for Infection Research (DZIF), partner site Charité, 10117 Berlin, Germany \\ 4: Department of Surgery, Duke University School of Medicine, Durham, NC, USA \\ 5: Duke Human Vaccine Institute, Duke University School of Medicine, Durham, NC, USA \\ 6: Department of Global Pediatric Medicine, Department of Infectious Diseases, St. Jude Children's Research Hospital, \\ Memphis, TN, USA \\ 7: Hospital Nacional Daniel A Carrión, Callao, Bellavista, Peru \\ 8: Department of Pathology, Duke University School of Medicine, Durham, NC, USA \\ 9: Erasmus Medical Center, Rotterdam, Netherlands \\ 10: School of Public Health, Universidad Peruana Cayetano Heredia, Lima, Peru \\ 11: Department of Pathobiological Science, School of Veterinary Medicine University of Wisconsin-Madison, Madison, WI, USA \\ 12: BC Centre for Disease Control, Vancouver, British Columbia, Canada \\ 13: Division of Virology, Institute of Medical Science, University of Tokyo, Tokyo, Japan \\ 14: The Research Center for Global Viral Diseases, National Center for Global Health and Medicine Research Institute, Tokyo, \\ Japan \\ 15: Department of Microbiology, Icahn School of Medicine at Mount Sinai, New York, NY, USA \\ 16: Department of Pathology, Cellular and Molecular Medicine, Icahn School of Medicine at Mount Sinai, New York, NY, USA \\ 17: Moderna, Inc., Cambridge, MA, USA \\ 18: Division of Infectious Diseases, Department of Medicine, Icahn School of Medicine at Mount Sinai, New York, NY, USA \\ 19: The Global Health and Emerging Pathogen Institute, Icahn School of Medicine at Mount Sinai, New York, NY, USA \\ 20: Division of Child and Adolescent Health, Department of Pediatrics, Columbia University Vagelos College of Physicians and \\ Surgeons, and Department of Population and Family Health, Mailman School of Public Health, New York, NY, USA \\ 21: Department of Genetics and Genomic Sciences, Icahn School of Medicine at Mount Sinai, New York, NY, USA \\ 22: Department of Infectious Diseases, St. Jude Children's Research Hospital, Memphis, TN, USA
}

* Contributed equally

\# Corresponding 


\section{Abstract}

During the SARS-CoV-2 pandemic, multiple variants with differing amounts of escape from pre-existing immunity have emerged, causing concerns about continued protection. Here, we use antigenic cartography to quantify and visualize the antigenic relationships among 16 SARS-CoV-2 variants titrated against serum samples taken post-vaccination and post-infection with seven different variants. We find major antigenic differences caused by substitutions at positions $417,452,484$, and possibly 501. B.1.1.529 (Omicron) showed the highest escape from all sera tested. Visualization of serological responses as antibody landscapes shows how reactivity clusters in different regions of antigenic space. We find changes in immunodominance of different spike regions depending on the variant an individual was exposed to, with implications for variant risk assessment and vaccine strain selection.

\section{Introduction}

Since the beginning of the Severe Acute Respiratory Syndrome Coronavirus 2 (SARS-CoV-2) pandemic, the virus has caused more than 290 million cases and 5 million deaths (1). During the first year of the pandemic, circulation was dominated by the B. 1 variant, characterized by the D614G substitution in the spike protein, which imparted increased infectivity and transmissibility in vitro and in animal models $(2,3)$ but did not escape serum neutralization (4). Since then, multiple variants have circulated widely, with five of them (B.1.1.7 (Alpha), B.1.351 (Beta), P.1 (Gamma), B.1.617.2 (Delta), and B.1.1.526 (Omicron)) categorized as Variants of Concern by the World Health Organization (WHO) based on evidence of higher transmissibility, increased virulence, and/or reduced effectiveness of vaccines, therapeutics or diagnostics (5). At the beginning of 2021, B.1.1.7 became the predominantly circulating variant in Europe and North America, P.1 and B.1.1.7 in South America, and B.1.351 and B.1.1.7 in Africa, and Asia. In the third quarter of 2021, those variants were largely replaced by B.1.617.2 worldwide (6). Between December 2021 and January 2022, most geographic areas witnessed a rapid spread of the B.1.1.529 (Omicron) variant, which is able to infect and transmit readily from vaccinated and non-vaccinated individuals (7).

Prior to the emergence of B.1.1.529, a number of variants circulating in 2021 were antigenically distinct from the B.1-like 2020 viruses, with B.1.351 most strongly escaping neutralizing activity by convalescent and post-vaccination sera $(8,9)$. Sera from individuals first infected with B.1.351 and P.1 fail to readily neutralize B.1.617.2, and vice versa, though B.1.617.2 does not show strong escape from convalescent sera after infection with B.1-like variants (10, 11). B.1.1.529 has substantial escape from post-vaccination and convalescent sera $(12,13)$.

Understanding the antigenic relationships among different variants in primary-infection serum responses, and the substitutions causing antigenic change, is important for evaluating the need for vaccine updates, and predicting whether newly arising variants may be able to evade immune responses induced by currently used vaccines. However, as the number of variants continues to increase, the task of understanding the antigenic relationships among variants from raw neutralization titer data becomes increasingly complex. Antigenic cartography (14) is a tool originally developed for the analysis of human seasonal influenza virus antigenic data and has since been used in the analysis of antigenic variation in other pathogens, including avian, equine and swine influenza viruses (15-19), flaviviruses (20) including dengue viruses (21, 22), lyssaviruses (23), and foot-and-mouth disease viruses (24). It allows a quantitative and visual summary of antigenic differences among a large number of variants and is a core component of the bi-annual influenza virus vaccine strain selection process convened by the WHO. Here, we use antigenic cartography to analyze patterns of cross-reactivity among a panel of 16 SARS-CoV-2 variants and eight groups of human sera obtained from individuals following primary infection with one of seven different variants or after mRNA-1273 vaccination.

\section{Results}

\section{Variant reactivity by serum group}

We used 126 serum samples collected from vaccinated or infected individuals (table S1) and titrated in a neutralization assay against lentiviral pseudotypes encoding the spike protein of 16 SARS-CoV-2 variants (table S2). The serum samples comprise seven different serum groups of individuals with sequence-confirmed or assumed primary infections with $D 614 G(n=15)$, B.1.1.7 $(n=14)$, B.1.351 $(n=19)$, P.1 $(n=17)$, B.1.617.2 $(n=12)$, B.1.526+E484K $(n=8)$, B.1.637 $(n=3)$ and C.37 $(n=10)$ variants. We also included an eighth group of sera collected from previously naive individuals vaccinated with the Moderna mRNA-1273 vaccine four weeks post second dose $(n=28)$ (table S1). 
Figures 1 and S1 show the geometric mean titer (GMT) and individual serum reactivity profiles for each group of sera. Within serum groups, patterns of reactivity were broadly consistent once variation in the overall magnitude of each individual response was accounted for (fig. S2). Less variation was seen in the post-vaccination sera than in D614G convalescent sera, both in terms of response magnitude and the pattern of reactivity seen against the variants. This is likely related to the more standardized dose (25) and nature of vaccination compared to infection (26-28) but may also be caused by varying time intervals between infection and sample collection seen in the convalescent samples compared to post-vaccination samples (table S1) (29). Additional variation in post-infection serum groups was often related to higher-than-expected titers against B.1.617.2-like variants, suggesting that in some cases, sera might be from individuals infected with B.1.617.2 variants after a primary infection with a different variant. GMTs were robust to the exclusion of these potentially second-exposure sera (fig. S3, Materials and Methods).

Comparing the post-vaccination and D614G sera responses to each other, we found that mean titers were consistently higher in post-vaccination sera. We also found that the fold-drop compared to the homologous D614G variant was smaller for several variants in the vaccinated group compared to the $\mathrm{D} 614 \mathrm{G}$ group of sera, particularly among variants showing larger reductions in neutralization, although there was substantial variation (fig. S4). This suggests that vaccination titers four weeks post second dose were not only higher than D614G convalescent titers, but the sera were also more cross-reactive.

In each of the serum groups against which B.1.1.529 was titrated (post-vaccination, B.1.351, B.1.617.2, and B.1.526+E484K sera), B.1.1.529 showed the largest fold-decline, ranging from an approximately 32-fold decline for both the post-vaccination and B.1.351 sera, up to an approximately 256-fold drop for the B.1.617.2 sera (Materials and Methods, figs. S5, S6).

\section{Antigenic cartography}

To visualize and quantify how the different variants relate to each other antigenically, we used the titrations shown in Fig. 1 to construct an antigenic map, where antigens and sera are positioned relative to each other such that the distance between them corresponds to the fold-drop compared to the maximum serum titer (Materials and Methods). Cross-validation results indicated that the neutralization data could be well represented in two dimensions, and the map was robust to assay noise and the exclusion of serum groups and variants (Materials and Methods, figs. S7-S19).

The resulting antigenic map (Fig. 2, fig. S20) can broadly be divided into six areas, corresponding to how the different variants group antigenically: 1) A left-middle area occupied by vaccine and D614G sera, as well as viruses that are well neutralized by those sera (D614G and B.1.1.7). 2) A top-right area with viruses neutralized well by B.1.351 and P.1 sera (P.1, B.1.351, B.1.621, B.1.1.7+E484K). 3) A middle-right area occupied by the B.1.526+E484K variant. 4) A bottom-left area with viruses (B.1.617.2, B.1.617.2+K417N, B.1.429) neutralized well by vaccine and D614G sera, as well as B.1.617.2 sera. 5) A bottom-right area with viruses not neutralized well by any sera (B.1.617.1, B.1.617.2+E484Q), and finally 6 ) the area occupied by the B.1.1.529 variant, which is positioned furthest away from the vaccine and D614G convalescent sera.

\section{Serological reactivity shown by antibody landscapes}

The antigenic map visualizes individual serum responses as separate points in the map based on fold-drop compared to the maximum serum titer. As an extension of the antigenic map visualization, antibody landscapes give an indication of how serum reactivity distributes after exposure to different variants, the magnitude of the response, and expected levels of reactivity to variants that have not been titrated (fig. S21). Figure 3 shows individual responses and mean estimates of the GMT for each serum group modeled as antibody landscape surfaces in a third dimension. Consistent with the raw titers in Fig.1, the shape of the antibody landscapes is similar for post-vaccination, D614G and B.1.1.7 serum groups, with the highest reactivity around the D614G and B.1.1.7 variants, albeit with higher titers for the post-vaccine sera landscape. Similarly, the shape of the landscapes generated by the B.1.351 and P.1 sera is comparable, with highest reactivity centered on the B.1.351 and P.1 variants. The landscape of the B.1.617.2 sera shows a contrasting topology to the B.1.351 and P.1 landscapes, with the highest reactivity against the B.1.617.2 variant and falling off towards other areas of the map. In agreement with the raw titers, the landscapes show that all sera investigated here would be expected to have markedly reduced reactivity against B.1.1.529 (Fig. 3, fig. S21).

\section{Molecular basis of the map topology}

The locations of variants in the antigenic map point to amino acid substitutions which are shared between variants with similar antigenic characteristics (Fig. 2). For example, variants with substitutions at position 484 (E to K or Q), are exclusively positioned on the right of the map due to poorer neutralization by $\mathrm{D} 614 \mathrm{G}$ and vaccine sera. Variants at the top right (B.1.351, P.1, B.1.621, B.1.1.7+E484K) all have a substitution at position 501 ( $\mathrm{N}$ to $\mathrm{Y}$ ), and B.1.351 and P.1 additionally have substitutions 
at position 417, suggesting that these changes may be associated with increased reactivity to B.1.351 and P.1 sera. Variants in the lower half of the map (B.1.617.2, B.1.429, C.37, B.1.617.1) all have substitutions at position 452 ( $L$ to $R$ or Q). While C.37 also showed rightwards movement, maybe indicating a role of its $\mathrm{F} 490 \mathrm{~S}$ substitution in causing antigenic change, there was a substantial difference in the amount of escape of this variant seen in either post-vaccination or D614G sera (Fig. 1, fig. S4), making the potential additional contribution of this substitution unclear.

To further investigate the molecular basis of these antigenic differences, we generated a series of lentivirus pseudotypes with substitutions in the receptor binding domain (RBD) and measured the effect on reactivity to different serum groups and the subsequent positioning of variants in the antigenic map (Fig. 4, figs. S22-S25). First, investigating the observation that the left to right antigenic divide was associated with changes at position 484, we separately introduced the substitutions E484K and E484Q into the background of D614G. We found that the D614G+E484K mutant was associated with an 11.6-fold drop (fig. $\mathrm{S} 23 \mathrm{~A}$ ) in reactivity to $\mathrm{D} 614 \mathrm{G}$ sera (95\% confidence interval $(\mathrm{Cl}) 7.1-18.9$ fold), while the D614G+E484Q mutant had a similarly significant, but smaller, 5.7-fold drop (95\% Cl 3.4-9.5) in reactivity (fig. S23C). In the antigenic map, this was consistent with a rightwards shift into the antigenic region occupied by variants that have these substitutions in common (B.1.526+E484K for D614G+E484K, and B.1.617.1 and B.1.617.2+E484Q for D614G+E484Q) (Fig. 4A).

We next investigated the role of $L 452 \mathrm{R}$ in mediating antigenic change and escape from $\mathrm{D} 614 \mathrm{G}$ serum reactivity. The $\mathrm{D} 614 \mathrm{G}+\mathrm{L} 452 \mathrm{R}$ mutant was associated with a drop of 2.1-fold (95\% Cl 1.7-2.6) against D614G sera compared to D614G alone (fig. S23E), supporting an antigenic effect of the L452R substitution. However, the combination of the L452R and $E 484 Q$ substitutions, which showed a fold-drop of 4.7 to D614G sera (95\% Cl 3-7.4) (fig S23F), while also moving right in the antigenic map (Fig. 4A), did not generate any additional escape from D614G sera reactivity as compared to E484Q alone, suggesting that the effects of these single substitutions were not additive in this case. The additional antigenic change seen in $\mathrm{B} .1 .617 .1$ toward the bottom right of the map, which showed an extra fold drop of 3.4 for $D 614 G$ sera compared to the $D 614 G+E 484 Q+L 452 R$ mutant (fig. S24), might therefore be caused by further substitutions outside of the RBD. Interestingly, the E484K, E484Q, and L452R+E484Q substitutions had no significant or little effect on the reactivity of B.1.351 sera (fig. S23B,D,G), suggesting that although these substitutions were able to create significant antigenic change in decreasing D614G sera reactivity, this had no effect on B.1.351 sera neutralization, with titers neither increasing with additional sequence homology to B.1.351 (D614G+E484K), nor decreasing with reduced homology (D614G+L452R+E484Q).

Finally, we investigated the effect of substitutions at position 417 by reverting that substitution in the B.1.351 and P.1 variants in the top right of the map back to the ancestral $\mathrm{K}$ and introducing $417 \mathrm{~N}$ into the B.1.429 and B.1.617.1 variants in the bottom left and bottom right of the map, respectively. Titers against B.1.351 sera were reduced by 2.9 -fold in the case of $\mathrm{B} .1 .351+\mathrm{N} 417 \mathrm{~K}$, and 2.2-fold for P.1+T417K (fig. S25A,B), while not significantly changing reactivity against D614G sera, and the substitution was associated with downwards movement in the antigenic map (Fig. 4B). For B.1.617.1+K417N the effect was the opposite, increasing reactivity to B.1.351 sera by 2.8-fold (fig. S25C) and causing subsequent upwards movement in the map (Fig. 4B). Introducing K417N into B.1.429 caused increases in reactivity of 1.7-fold and 2.3-fold to B.1.351 and D614G sera, respectively (fig. S25D). This increase in reactivity to D614G sera in addition to B.1.351 sera was unexpected, given that the $\mathrm{K} 417 \mathrm{~N}$ substitution represents a change away from sequence homology with D614G. Since it has been shown that the presence of the $\mathrm{K} 417 \mathrm{~N}$ substitution alone in the absence of $501 \mathrm{Y}$ greatly reduces angiotensin-converting enzyme 2 (ACE2) affinity in some contexts (30), we speculate that the effect seen in B.1.429+K417N may be an artificial inflation of titers generally, rather than true antigenic change. While the effect of the substitutions at position 417 introduced in P.1, B.1.351 and B.1.617.1 was more consistent with an underlying antigenic effect as inferred from the map, they did not fully change the antigenic phenotype between variants in the top right and bottom right of the map, suggesting that additional substitutions, for example the additional change identified at position 501, are also antigenically significant. A contribution of N501Y would further be consistent with the top-right position of B.1.1.7+E484K and B.1.621, both of which have E484K and N501Y in the RBD, without substitutions at position 417.

\section{Variation in immunodominance of different RBD sites between serum groups}

One pattern indicated in the antigenic map and tested by the mutant experiments was that substantial effects on reactivity to one serum group could be associated with little or no effect on the reactivity measured against another, indicative of changes in immunodominance. Figure 5 shows the titers of $\mathrm{D} 614 \mathrm{G}$ and B.1.351 sera for the $\mathrm{D} 614 \mathrm{G}$ and B.1.351 variants, along with titers against the $\mathrm{D} 614 \mathrm{G}+\mathrm{E} 484 \mathrm{~K}$ and $\mathrm{B} \cdot 1.351+\mathrm{K} 417 \mathrm{~N}$ variants. The B.1.526+E484K variant is shown as a comparator. While the neutralizing activity of $\mathrm{D} 614 \mathrm{G}$ sera against the $\mathrm{D} 614 \mathrm{G}+\mathrm{E} 484 \mathrm{~K}$ variant was substantially reduced as discussed above, there was little difference in neutralization of this variant by B.1.351 convalescent sera (Fig. 5A,B and fig. S23A,B). Reciprocally, while substitutions introduced at position 417 consistently affected B.1.351 serum reactivity, there was little effect on the reactivity of D614G sera (Fig. 5C,D and fig. S25B). 
We tested for further evidence of immunodominance switches in the serum groups more generally by comparing differences in serum reactivity between pairs of variants that differed by single amino acid changes in the RBD. Comparing pairs of variants with differences at position 484 (B.1.526+E484K vs D614G; B.1.1.7+E484K vs B.1.1.7; B.1.617.2+E484Q vs B.1.617.2) (fig. S26A-C), the findings were consistent with those from the D614G+E484K mutant, with D614G sera consistently showing significantly reduced reactivity when the amino acid at position 484 varied from the ancestral $484 \mathrm{E}$, while the B.1.351 sera showed little to no significant change in reactivity. These observations also extended to the other serum groups, with the overall pattern being that sera from individuals infected with variants with the ancestral 484E (vaccine, D614G, B.1.1.7 and B.1.617.2 sera) were sensitive to differences at position 484 , while sera from infections with 484K (B.1.351, P.1 and B.1.526+E484K sera) were not affected by these substitutions. C.37, with a substitution close to 484 at 490 , was an exception. These sera also displayed little sensitivity to amino acid difference at position 484 for the one pair of variants where it could be compared (fig. S26C).

Comparing pairs of variants with differences at spike position 417 (B.1.617.2+K417N vs B.1.617.2, P.1 vs B.1.1.7+E484K) (fig. S27), results were mixed. Differences between B.1.1.7+E484K and P.1 were consistent with experimental results in B.1.351+N417K and P.1+T417K, where B.1.351 sera were generally sensitive to differences at 417 while D614G sera were not. For B.1.617.2+K417N vs B.1.617.2, little difference was observed between D614G and B.1.351 sera, reminiscent of the mutant results seen with $B .1 .429+K 417 \mathrm{~N}$ and also suggesting a possible interaction with presence or absence of an associated substitution, 501Y. For P.1 vs B.1.1.7+E484K we also noted a wider general trend where serum groups associated with changes to $417 \mathrm{~T} / \mathrm{N}$ (P.1, B.1.351 sera) tended to have higher reactivity against variants with $\mathrm{K} 417 \mathrm{~N}$, while those with ancestral $417 \mathrm{~K}$ (post-vaccination, D614G, B.1.1.7, B.1.526+E484K, B.1.617.2, and C.37 sera) showed less evidence of a sensitivity to the substitution.

Considering pairs of variants differing at spike position 501 (B.1.1.7 vs D614G and B.1.1.7+E484K vs B.1.526+E484K) (fig. S28), we again noted distinctions between serum groups, with B.1.351 and B.1.1.7 sera (with $501 \mathrm{Y}$ ) generally being sensitive to differences at position 501, while vaccine sera and D614G, B.1.526+E484K, and B.1.617.2 sera (with ancestral 501N) were not sensitive to the same extent. Interestingly, the P.1 serum group did not seem to be sensitive to changes at position 501 , despite its homologous variant having the N501Y substitution.

Finally, two variants (D614G vs B.1.429) allowed for a comparison of the effects of a substitution at 452 . In keeping with the effect of the $D 614 G+L 452 R$ mutant in $D 614 G$ sera and lack of effect seen of the $D 614 G+L 452 R+E 484 Q$ variant in $B .1 .351$ sera, D614G sera showed significantly reduced reactivity to B.1.429, which has $452 \mathrm{R}$, while B.1.351 sera had similar titers against the two variants (fig. S29). Aside from B.1.351 and B.1.526+E484K, all other serum groups distinguished between the two variants, with decreased (vaccine, D614G, B.1.1.7, and P.1 sera) or increased (B.1.617.2 sera) titers to B.1.429, corresponding to the amino acid present at position 452 in the eliciting variant.

These patterns indicate that different serum groups display distinct patterns of immunodominance in terms of the regions on the RBD that are preferentially targeted by antibodies, and subsequently the types of substitutions to which the different sera are sensitive. These observations can also explain wider patterns in the data, for example why the B.1.1.7 variant, with N501Y in the RBD, does not significantly escape reactivity to vaccine or D614G sera (fig. S5A,B), yet is neutralized more efficiently by B.1.351 sera as compared to the D614G variant (fig. S5E). We also note that although for some positions, such as 484 , a change in amino acid could be associated with a change in immunodominance of that position, this was not always the case. For example, B.1.351 sera appeared insensitive to amino acid changes at position 452 while D614G sera were sensitive to substitutions at that position, despite the fact that both B.1.351 and D614G carry a Leucine at position 452, suggesting that the immunodominance patterns may sometimes depend on more complex context-based effects.

\section{Discussion}

The antigenic analyses of SARS-CoV-2 variants presented here underscore the advantages of an integrated and extensible framework for understanding antigenic relationships and serum responses in SARS-CoV-2. We find that different variants and serum responses cluster in a way that allows the inference of prime candidates for the amino acid substitutions responsible for the antigenic changes. Testing inferences from this approach experimentally, we find antigenic effects that are consistent with those inferred from antigenic map topology. Findings on the significant role of substitutions at position 484 and suggestions of the role of 417 and 501 are in agreement with other work based on deep mutational scanning (DMS) (31-33) and neutralization data using vesicular stomatitis virus pseudotyped particles $(34,35)$. Extending the current map with additional variants and sera, in particular sera that are able to potently neutralize variants in the bottom right area of the map (B.1.617.1, B.1.617.2+E484Q, and B.1.1.529), will increase the resolution of this portion of the map and help guide further work to identify the broader range of substitutions and positions associated with SARS-CoV-2 antigenic evolution in both current and future variants. 
Although we find that B.1.1.529 shows the greatest escape of all variants we tested, it is perhaps surprising, given it has 15 substitutions in the RBD, that compared to other variants its escape was not greater. B.1.1.529 shows only 2.3-fold additional escape from vaccine sera as compared to the B.1.351 variant, 2.4-fold additional escape from B.1.351 sera as compared to the B.1.617.2 variant, and similar antigenic escape from B.1.617.2 sera as compared to the B.1.621 variant (fig. S5). Our finding of a 30-fold decline from D614G to B.1.1.529 in the vaccination group falls at the center of the range of published values for twice Moderna mRNA-1273 vaccinated individuals, which ranges from 8-fold to approximately 80-fold with a mean of 30-fold (13). The large range in published estimates for fold-decline in B.1.1.529 neutralization might come from differences in the assay used and the presence of high numbers of non-detectable titers. Although fewer studies report neutralization data against variant sera, there is no evidence that our measurements are substantially different from what others report (13).

The large antigenic effect of single substitutions such as E484K is reminiscent of human influenza viruses, where, among circulating strains that may differ by amino acids at multiple positions, a large portion of the antigenic difference is associated with only a single or double substitution (36), and similarly for swine and equine influenza viruses (37, 38). For influenza virus, these substitutions are located adjacent to the receptor binding site on the hemagglutinin protein, which is also observed for the determinants of SARS-CoV-2 antigenic evolution described here, being located close to the ACE2 binding site on the spike protein (fig. S30, S31). Given that B.1.1.529 differs from B.1.351 by substitutions at 11 additional positions in the RBD, yet is only 2.3-fold less sensitive to neutralization by the vaccine sera compared to B.1.351 (fig. S5), it is plausible that a similar pattern applies here, where the majority of these substitutions are not associated with significant antigenic effects. In this regard, tests of the substitutions present in B.1.1.529 $(31,33,35)$ identify significant effects of K417N, E484A, Q493R, G446S, and N501Y on reducing monoclonal antibody binding. Given the presence of K417N and N501Y in B.1.351 and the apparent insensitivity of vaccine and D614G post-infection sera to substitutions at these positions, it is not likely they would explain the additional escape. Changes at position 484 have already been implicated, with E484A causing more escape from D614G sera than E484K in deep mutational scanning data (31), and the remaining substitutions, G446S and Q493R, would also fit the general pattern of proximity to the receptor binding site (fig. S31). The effect of G446S is predominantly to antibodies binding to Barnes class III positions in the 443-450 loop $(31,35,39)$, a region that is relatively less targeted by antibodies generated by D614G infections (31). E484A and Q493R show substantial effects on reducing binding by antibodies targeting Barnes class II positions (on the outer face of the receptor binding ridge) $(31,35,39)$, making them seemingly likely candidates for additional escape against D614G and vaccine sera, which primarily target this region (31).

The antigenic map, in combination with the antibody landscapes, allows us to understand and compare serum responses not only on a variant by variant basis, but also more generally, providing a quantitative measurement of both the magnitude and breadth of response following different exposures, while using information on antigenic relationships in the map to infer how reactivity is likely to distribute to variants that have not been measured. Although the sera investigated here represent single exposures, the same principles can be applied for understanding how multi-exposure serum responses distribute across antigenic space (40). With an increasing number of variants to choose from to update SARS-CoV-2 vaccines, the capacity to rationally select variants that represent a full range of SARS-CoV-2 antigenic variation will become increasingly important for guiding vaccine strain selection and testing of sera, both in the context of determining the antigenic variants against which a population may have low protection, and for effectively comparing the antigenic breadth of vaccine-elicited responses.

Our findings indicating switches in immunodominance, where sera preferentially target different regions of the RBD depending on the variant an individual is first exposed to, have potential consequences for future variant risk assessment and vaccine immunogen selection. Similar behavior has been seen in influenza virus (41), and the findings are consistent with studies in SARS-CoV-2 showing that monoclonal antibodies tend to have differing regional binding preferences when sourced from individuals exposed to different variants $(11,42-44)$. In addition, conclusions of an immunodominance switch for B.1.351 sera away from the 484 region correspond well with recently published data applying deep mutational scanning techniques to sera post D614G and B.1.351 infection (32). Our results show how such immunodominance switches extend to vaccination and infections with different variants. As populations increasingly experience multiple exposures, it will be important to investigate responses with these immunodominance patterns in mind. In particular, how responses to vaccination with new variants may consequently differ from the types of response inferred from first exposure sera and animal models, which may have preferentially targeted different epitopes. Answers to these questions will reveal the variants and substitutions to which different populations are most vulnerable and help anticipate which emerging variants may be most at risk of evading current immunity. As understanding increases, the choice of vaccine immunogens based on immunodominance considerations may be as important as their antigenic characteristics. 


\section{References}

1. WHO Covid Update 06.01.2022, (available at

https://www.who.int/publications/m/item/weekly-epidemiological-update-on-covid-19---6-january-2022).

2. B. Korber, W. M. Fischer, S. Gnanakaran, H. Yoon, J. Theiler, W. Abfalterer, N. Hengartner, E. E. Giorgi, T. Bhattacharya, B. Foley, K. M. Hastie, M. D. Parker, D. G. Partridge, C. M. Evans, T. M. Freeman, T. I. de Silva, Sheffield COVID-19 Genomics Group, C. McDanal, L. G. Perez, H. Tang, A. Moon-Walker, S. P. Whelan, C. C. LaBranche, E. O. Saphire, D. C. Montefiori, Tracking Changes in SARS-CoV-2 Spike: Evidence that D614G Increases Infectivity of the COVID-19 Virus. Cell. 182, 812-827.e19 (2020).

3. Y. J. Hou, S. Chiba, P. Halfmann, C. Ehre, M. Kuroda, K. H. Dinnon 3rd, S. R. Leist, A. Schäfer, N. Nakajima, K. Takahashi, R. E. Lee, T. M. Mascenik, R. Graham, C. E. Edwards, L. V. Tse, K. Okuda, A. J. Markmann, L. Bartelt, A. de Silva, D. M. Margolis, R. C. Boucher, S. H. Randell, T. Suzuki, L. E. Gralinski, Y. Kawaoka, R. S. Baric, SARS-CoV-2 D614G variant exhibits efficient replication ex vivo and transmission in vivo. Science. 370 , 1464-1468 (2020).

4. D. Weissman, M.-G. Alameh, T. de Silva, P. Collini, H. Hornsby, R. Brown, C. C. LaBranche, R. J. Edwards, L. Sutherland, S. Santra, K. Mansouri, S. Gobeil, C. McDanal, N. Pardi, N. Hengartner, P. J. C. Lin, Y. Tam, P. A. Shaw, M. G. Lewis, C. Boesler, U. Şahin, P. Acharya, B. F. Haynes, B. Korber, D. C. Montefiori, D614G Spike Mutation Increases SARS CoV-2 Susceptibility to Neutralization. Cell Host Microbe. 29, 23-31.e4 (2021).

5. Tracking SARS-CoV-2 variants, (available at https://www.who.int/en/activities/tracking-SARS-CoV-2-variants).

6. CoVariants, (available at https://covariants.org/).

7. R. Viana, S. Moyo, D. G. Amoako, H. Tegally, C. Scheepers, C. L. Althaus, U. J. Anyaneji, P. A. Bester, M. F. Boni, M. Chand, W. T. Choga, R. Colquhoun, M. Davids, K. Deforche, D. Doolabh, L. du Plessis, S. Engelbrecht, J. Everatt, J. Giandhari, M. Giovanetti, D. Hardie, V. Hill, N.-Y. Hsiao, A. Iranzadeh, A. Ismail, C. Joseph, R. Joseph, L. Koopile, S. L. Kosakovsky Pond, M. U. G. Kraemer, L. Kuate-Lere, O. Laguda-Akingba, O. Lesetedi-Mafoko, R. J. Lessells, S. Lockman, A. G. Lucaci, A. Maharaj, B. Mahlangu, T. Maponga, K. Mahlakwane, Z. Makatini, G. Marais, D. Maruapula, K. Masupu, M. Matshaba, S. Mayaphi, N. Mbhele, M. B. Mbulawa, A. Mendes, K. Mlisana, A. Mnguni, T. Mohale, M. Moir, K. Moruisi, M. Mosepele, G. Motsatsi, M. S. Motswaledi, T. Mphoyakgosi, N. Msomi, P. N. Mwangi, Y. Naidoo, N. Ntuli, M. Nyaga, L. Olubayo, S. Pillay, B. Radibe, Y. Ramphal, U. Ramphal, J. E. San, L. Scott, R. Shapiro, L. Singh, P. Smith-Lawrence, W. Stevens, A. Strydom, K. Subramoney, N. Tebeila, D. Tshiabuila, J. Tsui, S. van Wyk, S. Weaver, C. K. Wibmer, E. Wilkinson, N. Wolter, A. E. Zarebski, B. Zuze, D. Goedhals, W. Preiser, F. Treurnicht, M. Venter, C. Williamson, O. G. Pybus, J. Bhiman, A. Glass, D. P. Martin, A. Rambaut, S. Gaseitsiwe, A. von Gottberg, T. de Oliveira, Rapid epidemic expansion of the SARS-CoV-2 Omicron variant in southern Africa. Nature (2022), doi:10.1038/d41586-021-03832-5.

8. W. F. Garcia-Beltran, E. C. Lam, K. St. Denis, A. D. Nitido, Z. H. Garcia, B. M. Hauser, J. Feldman, M. N. Pavlovic, D. J. Gregory, M. C. Poznansky, A. Sigal, A. G. Schmidt, A. John lafrate, V. Naranbhai, A. B. Balazs, Multiple SARS-CoV-2 variants escape neutralization by vaccine-induced humoral immunity. Cell. 184 (2021), p. 2523.

9. C. Lucas, C. B. F. Vogels, I. Yildirim, J. E. Rothman, P. Lu, V. Monteiro, J. R. Gehlhausen, M. Campbell, J. Silva, A. Tabachnikova, M. A. Peña-Hernandez, M. C. Muenker, M. I. Breban, J. R. Fauver, S. Mohanty, J. Huang, Yale SARS-CoV-2 Genomic Surveillance Initiative, A. C. Shaw, A. I. Ko, S. B. Omer, N. D. Grubaugh, A. Iwasaki, Impact of circulating SARS-CoV-2 variants on mRNA vaccine-induced immunity. Nature. 600, 523-529 (2021).

10. L. Dupont, L. B. Snell, C. Graham, J. Seow, B. Merrick, T. Lechmere, T. J. A. Maguire, S. R. Hallett, S. Pickering, T. Charalampous, A. Alcolea-Medina, I. Huettner, J. M. Jimenez-Guardeño, S. Acors, N. Almeida, D. Cox, R. E. Dickenson, R. P. Galao, N. Kouphou, M. J. Lista, A. M. Ortega-Prieto, H. Wilson, H. Winstone, C. Fairhead, J. Z. Su, G. Nebbia, R. Batra, S. Neil, M. Shankar-Hari, J. D. Edgeworth, M. H. Malim, K. J. Doores, Neutralizing antibody activity in convalescent sera from infection in humans with SARS-CoV-2 and variants of concern. Nat Microbiol. 6, 1433-1442 (2021).

11. C. Liu, H. M. Ginn, W. Dejnirattisai, P. Supasa, B. Wang, A. Tuekprakhon, R. Nutalai, D. Zhou, A. J. Mentzer, Y. Zhao, H. M. E. Duyvesteyn, C. López-Camacho, J. Slon-Campos, T. S. Walter, D. Skelly, S. A. Johnson, T. G. Ritter, C. Mason, S. A. Costa Clemens, F. Gomes Naveca, V. Nascimento, F. Nascimento, C. Fernandes da Costa, P. C. Resende, A. Pauvolid-Correa, M. M. Siqueira, C. Dold, N. Temperton, T. Dong, A. J. Pollard, J. C. 
bioRxiv preprint doi: https://doi.org/10.1101/2022.01.28.477987; this version posted January 28,2022 . The copyright holder for this preprint (which was not certified by peer review) is the author/funder, who has granted bioRxiv a license to display the preprint in perpetuity. It is made available under aCC-BY-NC-ND 4.0 International license.

Knight, D. Crook, T. Lambe, E. Clutterbuck, S. Bibi, A. Flaxman, M. Bittaye, S. Belij-Rammerstorfer, S. C. Gilbert, T. Malik, M. W. Carroll, P. Klenerman, E. Barnes, S. J. Dunachie, V. Baillie, N. Serafin, Z. Ditse, K. Da Silva, N. G. Paterson, M. A. Williams, D. R. Hall, S. Madhi, M. C. Nunes, P. Goulder, E. E. Fry, J. Mongkolsapaya, J. Ren, D. I. Stuart, G. R. Screaton, Reduced neutralization of SARS-CoV-2 B.1.617 by vaccine and convalescent serum. Cell. 184, 4220-4236.e13 (2021).

12. W. Dejnirattisai, J. Huo, D. Zhou, J. Zahradník, P. Supasa, C. Liu, H. M. E. Duyvesteyn, H. M. Ginn, A. J. Mentzer, A. Tuekprakhon, R. Nutalai, B. Wang, A. Dijokaite, S. Khan, O. Avinoam, M. Bahar, D. Skelly, S. Adele, S. A. Johnson, A. Amini, T. Ritter, C. Mason, C. Dold, D. Pan, S. Assadi, A. Bellass, N. Omo-Dare, D. Koeckerling, A. Flaxman, D. Jenkin, P. K. Aley, M. Voysey, S. A. Costa Clemens, F. G. Naveca, V. Nascimento, F. Nascimento, C. Fernandes da Costa, P. C. Resende, A. Pauvolid-Correa, M. M. Siqueira, V. Baillie, N. Serafin, G. Kwatra, K. Da Silva, S. A. Madhi, M. C. Nunes, T. Malik, P. J. M. Openshaw, J. K. Baillie, M. G. Semple, A. R. Townsend, K.-Y. A. Huang, T. K. Tan, M. W. Carroll, P. Klenerman, E. Barnes, S. J. Dunachie, B. Constantinides, H. Webster, D. Crook, A. J. Pollard, T. Lambe, N. G. Paterson, M. A. Williams, D. R. Hall, E. E. Fry, J. Mongkolsapaya, J. Ren, G. Schreiber, D. I. Stuart, G. R. Screaton, SARS-CoV-2 Omicron-B.1.1.529 leads to widespread escape from neutralizing antibody responses. Cell (2022), doi:10.1016/j.cell.2021.12.046.

13. A. Netzl, S. Tureli, E. LeGresley, B. Mühlemann, S. H. Wilks, D. J. Smith, Analysis of SARS-CoV-2 Omicron Neutralization Data up to 2021-12-22. bioRxiv (2022), p. 2021.12.31.474032.

14. D. J. Smith, A. S. Lapedes, J. C. de Jong, T. M. Bestebroer, G. F. Rimmelzwaan, A. D. M. Osterhaus, R. A. M. Fouchier, Mapping the Antigenic and Genetic Evolution of Influenza Virus. Science. 305 (2004), pp. 371-376.

15. Y. Wang, I. Davidson, R. Fouchier, E. Spackman, Antigenic Cartography of H9 Avian Influenza Virus and Its Application to Vaccine Selection. Avian Dis. 60, 218-225 (2016).

16. A. L. Woodward, A. S. Rash, D. Blinman, S. Bowman, T. M. Chambers, J. M. Daly, A. Damiani, S. Joseph, N. Lewis, J. W. McCauley, L. Medcalf, J. Mumford, J. R. Newton, A. Tiwari, N. A. Bryant, D. M. Elton, Development of a surveillance scheme for equine influenza in the UK and characterisation of viruses isolated in Europe, Dubai and the USA from 2010-2012. Vet. Microbiol. 169, 113-127 (2014).

17. C. S. Anderson, P. R. McCall, H. A. Stern, H. Yang, D. J. Topham, Antigenic cartography of H1N1 influenza viruses using sequence-based antigenic distance calculation. BMC Bioinformatics. 19, 51 (2018).

18. S. Chepkwony, A. Parys, E. Vandoorn, W. Stadejek, J. Xie, J. King, A. Graaf, A. Pohlmann, M. Beer, T. Harder, $\mathrm{K}$. Van Reeth, Genetic and antigenic evolution of $\mathrm{H} 1$ swine influenza A viruses isolated in Belgium and the Netherlands from 2014 through 2019. Sci. Rep. 11, 11276 (2021).

19. D. M. Danilenko, A. B. Komissarov, A. V. Fadeev, M. I. Bakaev, A. A. Ivanova, P. A. Petrova, A. D. Vassilieva, K. S. Komissarova, A. I. Zheltukhina, N. I. Konovalova, A. V. Vasin, Antigenic and Genetic Characterization of Swine Influenza Viruses Identified in the European Region of Russia, 2014-2020. Front. Microbiol. 12, 662028 (2021).

20. A. Lorusso, V. Marini, A. Di Gennaro, G. F. Ronchi, C. Casaccia, G. Carelli, G. Passantino, N. D’Alterio, V. D'Innocenzo, G. Savini, F. Monaco, D. L. Horton, Antigenic relationship among zoonotic flaviviruses from Italy. Infect. Genet. Evol. 68, 91-97 (2019).

21. L. C. Katzelnick, J. M. Fonville, G. D. Gromowski, J. Bustos Arriaga, A. Green, S. L. James, L. Lau, M. Montoya, C. Wang, L. A. VanBlargan, C. A. Russell, H. M. Thu, T. C. Pierson, P. Buchy, J. G. Aaskov, J. L. Muñoz-Jordán, N. Vasilakis, R. V. Gibbons, R. B. Tesh, A. D. M. E. Osterhaus, R. A. M. Fouchier, A. Durbin, C. P. Simmons, E. C. Holmes, E. Harris, S. S. Whitehead, D. J. Smith, Dengue viruses cluster antigenically but not as discrete serotypes. Science. 349, 1338-1343 (2015).

22. L. C. Katzelnick, A. Coello Escoto, A. T. Huang, B. Garcia-Carreras, N. Chowdhury, I. Maljkovic Berry, C. Chavez, P. Buchy, V. Duong, P. Dussart, G. Gromowski, L. Macareo, B. Thaisomboonsuk, S. Fernandez, D. J. Smith, R. Jarman, S. S. Whitehead, H. Salje, D. A. T. Cummings, Antigenic evolution of dengue viruses over 20 years. Science. 374, 999-1004 (2021).

23. T. Nolden, A. C. Banyard, S. Finke, A. R. Fooks, D. Hanke, D. Höper, D. L. Horton, T. C. Mettenleiter, T. Müller, J. P. Teifke, C. M. Freuling, Comparative studies on the genetic, antigenic and pathogenic characteristics of Bokeloh bat lyssavirus. J. Gen. Virol. 95, 1647-1653 (2014).

24. A. B. Ludi, D. L. Horton, Y. Li, M. Mahapatra, D. P. King, N. J. Knowles, C. A. Russell, D. J. Paton, J. L. N. Wood, D. J. Smith, J. M. Hammond, Antigenic variation of foot-and-mouth disease virus serotype A. J. Gen. 
bioRxiv preprint doi: https://doi.org/10.1101/2022.01.28.477987; this version posted January 28,2022 . The copyright holder for this preprint (which was not certified by peer review) is the author/funder, who has granted bioRxiv a license to display the preprint in perpetuity. It is made available under aCC-BY-NC-ND 4.0 International license.

Virol. 95, 384-392 (2014).

25. B. Ying, B. Whitener, L. A. VanBlargan, A. O. Hassan, S. Shrihari, C.-Y. Liang, C. E. Karl, S. Mackin, R. E. Chen, N. M. Kafai, S. H. Wilks, D. J. Smith, J. M. Carreño, G. Singh, F. Krammer, A. Carfi, S. M. Elbashir, D. K. Edwards, L. B. Thackray, M. S. Diamond, Protective activity of mRNA vaccines against ancestral and variant SARS-CoV-2 strains. Sci. Transl. Med., eabm3302 (2021).

26. K. Röltgen, S. D. Boyd, Antibody and B cell responses to SARS-CoV-2 infection and vaccination. Cell Host Microbe. 29, 1063-1075 (2021).

27. Z. Wang, F. Muecksch, D. Schaefer-Babajew, S. Finkin, C. Viant, C. Gaebler, H.-H. Hoffmann, C. O. Barnes, M. Cipolla, V. Ramos, T. Y. Oliveira, A. Cho, F. Schmidt, J. Da Silva, E. Bednarski, L. Aguado, J. Yee, M. Daga, M. Turroja, K. G. Millard, M. Jankovic, A. Gazumyan, Z. Zhao, C. M. Rice, P. D. Bieniasz, M. Caskey, T. Hatziioannou, M. C. Nussenzweig, Naturally enhanced neutralizing breadth against SARS-CoV-2 one year after infection. Nature. 595, 426-431 (2021).

28. E. M. Anderson, T. Eilola, E. Goodwin, M. J. Bolton, S. Gouma, R. R. Goel, M. M. Painter, S. A. Apostolidis, D. Mathew, D. Dunbar, D. Fiore, A. Brock, J. Weaver, J. S. Millar, S. DerOhannessian, A. R. Greenplate, I. Frank, D. J. Rader, E. J. Wherry, S. E. Hensley, The UPenn COVID Processing Unit, SARS-CoV-2 infections elicit higher levels of original antigenic sin antibodies compared to SARS-CoV-2 mRNA vaccinations. bioRxiv (2021), , doi:10.1101/2021.09.30.21264363.

29. K. L. Lynch, J. D. Whitman, N. P. Lacanienta, E. W. Beckerdite, S. A. Kastner, B. R. Shy, G. M. Goldgof, A. G. Levine, S. P. Bapat, S. L. Stramer, J. H. Esensten, A. W. Hightower, C. Bern, A. H. B. Wu, Magnitude and Kinetics of Anti-Severe Acute Respiratory Syndrome Coronavirus 2 Antibody Responses and Their Relationship to Disease Severity. Clin. Infect. Dis. 72, 301-308 (2021).

30. M. Yuan, D. Huang, C.-C. D. Lee, N. C. Wu, A. M. Jackson, X. Zhu, H. Liu, L. Peng, M. J. van Gils, R. W. Sanders, D. R. Burton, S. M. Reincke, H. Prüss, J. Kreye, D. Nemazee, A. B. Ward, I. A. Wilson, Structural and functional ramifications of antigenic drift in recent SARS-CoV-2 variants. Science. 373, 818-823 (2021).

31. A. J. Greaney, T. N. Starr, C. O. Barnes, Y. Weisblum, F. Schmidt, M. Caskey, C. Gaebler, A. Cho, M. Agudelo, S. Finkin, Z. Wang, D. Poston, F. Muecksch, T. Hatziioannou, P. D. Bieniasz, D. F. Robbiani, M. C. Nussenzweig, P. J. Bjorkman, J. D. Bloom, Mapping mutations to the SARS-CoV-2 RBD that escape binding by different classes of antibodies. Nat. Commun. 12, 4196 (2021).

32. A. J. Greaney, T. N. Starr, R. T. Eguia, A. N. Loes, K. Khan, F. Karim, S. Cele, J. E. Bowen, J. K. Logue, D. Corti, D. Veesler, H. Y. Chu, A. Sigal, J. D. Bloom, A SARS-CoV-2 variant elicits an antibody response with a shifted immunodominance hierarchy. bioRxiv (2021), doi:10.1101/2021.10.12.464114.

33. Y. Cao, J. Wang, F. Jian, T. Xiao, W. Song, A. Yisimayi, W. Huang, Q. Li, P. Wang, R. An, J. Wang, Y. Wang, X. Niu, S. Yang, H. Liang, H. Sun, T. Li, Y. Yu, Q. Cui, S. Liu, X. Yang, S. Du, Z. Zhang, X. Hao, F. Shao, R. Jin, X. Wang, J. Xiao, Y. Wang, X. S. Xie, Omicron escapes the majority of existing SARS-CoV-2 neutralizing antibodies. Nature (2021), doi:10.1038/s41586-021-04385-3.

34. P. Wang, M. S. Nair, L. Liu, S. Iketani, Y. Luo, Y. Guo, M. Wang, J. Yu, B. Zhang, P. D. Kwong, B. S. Graham, J. R. Mascola, J. Y. Chang, M. T. Yin, M. Sobieszczyk, C. A. Kyratsous, L. Shapiro, Z. Sheng, Y. Huang, D. D. Ho, Antibody resistance of SARS-CoV-2 variants B.1.351 and B.1.1.7. Nature. 593, 130-135 (2021).

35. L. Liu, S. Iketani, Y. Guo, J. F.-W. Chan, M. Wang, L. Liu, Y. Luo, H. Chu, Y. Huang, M. S. Nair, J. Yu, K. K.-H. Chik, T. T.-T. Yuen, C. Yoon, K. K.-W. To, H. Chen, M. T. Yin, M. E. Sobieszczyk, Y. Huang, H. H. Wang, Z. Sheng, K.-Y. Yuen, D. D. Ho, Striking Antibody Evasion Manifested by the Omicron Variant of SARS-CoV-2. bioRxiv (2021), p. 2021.12.14.472719.

36. B. F. Koel, D. F. Burke, T. M. Bestebroer, S. van der Vliet, G. C. M. Zondag, G. Vervaet, E. Skepner, N. S. Lewis, M. I. J. Spronken, C. A. Russell, M. Y. Eropkin, A. C. Hurt, I. G. Barr, J. C. de Jong, G. F. Rimmelzwaan, A. D. M. E. Osterhaus, R. A. M. Fouchier, D. J. Smith, Substitutions near the receptor binding site determine major antigenic change during influenza virus evolution. Science. 342, 976-979 (2013).

37. N. S. Lewis, J. M. Daly, C. A. Russell, D. L. Horton, E. Skepner, N. A. Bryant, D. F. Burke, A. S. Rash, J. L. N. Wood, T. M. Chambers, R. A. M. Fouchier, J. A. Mumford, D. M. Elton, D. J. Smith, Antigenic and genetic evolution of equine influenza A (H3N8) virus from 1968 to 2007. J. Virol. 85, 12742-12749 (2011).

38. N. S. Lewis, T. K. Anderson, P. Kitikoon, E. Skepner, D. F. Burke, A. L. Vincent, Substitutions near the 
bioRxiv preprint doi: https://doi.org/10.1101/2022.01.28.477987; this version posted January $28,2022$. The copyright holder for this preprint (which was not certified by peer review) is the author/funder, who has granted bioRxiv a license to display the preprint in perpetuity. It is made available under aCC-BY-NC-ND 4.0 International license.

hemagglutinin receptor-binding site determine the antigenic evolution of influenza A H3N2 viruses in U.S. swine. J. Virol. 88, 4752-4763 (2014).

39. C. O. Barnes, C. A. Jette, M. E. Abernathy, K.-M. A. Dam, S. R. Esswein, H. B. Gristick, A. G. Malyutin, N. G. Sharaf, K. E. Huey-Tubman, Y. E. Lee, D. F. Robbiani, M. C. Nussenzweig, A. P. West Jr, P. J. Bjorkman, SARS-CoV-2 neutralizing antibody structures inform therapeutic strategies. Nature. 588, 682-687 (2020).

40. J. M. Fonville, S. H. Wilks, S. L. James, A. Fox, M. Ventresca, M. Aban, L. Xue, T. C. Jones, N. M. H. Le, Q. T. Pham, N. D. Tran, Y. Wong, A. Mosterin, L. C. Katzelnick, D. Labonte, T. T. Le, G. van der Net, E. Skepner, C. A. Russell, T. D. Kaplan, G. F. Rimmelzwaan, N. Masurel, J. C. de Jong, A. Palache, W. E. P. Beyer, Q. M. Le, T. H. Nguyen, H. F. L. Wertheim, A. C. Hurt, A. D. M. E. Osterhaus, I. G. Barr, R. A. M. Fouchier, P. W. Horby, D. J. Smith, Antibody landscapes after influenza virus infection or vaccination. Science. 346, 996-1000 (2014).

41. L. Popova, K. Smith, A. H. West, P. C. Wilson, J. A. James, L. F. Thompson, G. M. Air, Immunodominance of antigenic site B over site A of hemagglutinin of recent H3N2 influenza viruses. PLoS One. 7, e41895 (2012).

42. P. Supasa, D. Zhou, W. Dejnirattisai, C. Liu, A. J. Mentzer, H. M. Ginn, Y. Zhao, H. M. E. Duyvesteyn, R. Nutalai, A. Tuekprakhon, B. Wang, G. C. Paesen, J. Slon-Campos, C. López-Camacho, B. Hallis, N. Coombes, K. R. Bewley, S. Charlton, T. S. Walter, E. Barnes, S. J. Dunachie, D. Skelly, S. F. Lumley, N. Baker, I. Shaik, H. E. Humphries, K. Godwin, N. Gent, A. Sienkiewicz, C. Dold, R. Levin, T. Dong, A. J. Pollard, J. C. Knight, P. Klenerman, D. Crook, T. Lambe, E. Clutterbuck, S. Bibi, A. Flaxman, M. Bittaye, S.

Belij-Rammerstorfer, S. Gilbert, D. R. Hall, M. A. Williams, N. G. Paterson, W. James, M. W. Carroll, E. E. Fry, J. Mongkolsapaya, J. Ren, D. I. Stuart, G. R. Screaton, Reduced neutralization of SARS-CoV-2 B.1.1.7 variant by convalescent and vaccine sera. Cell. 184, 2201-2211.e7 (2021).

43. Evidence of escape of SARS-CoV-2 variant B.1.351 from natural and vaccine-induced sera. Cell. 184, 2348-2361.e6 (2021).

44. C. Liu, D. Zhou, R. Nutalai, H. M. E. Duyvesteyn, A. Tuekprakhon, H. M. Ginn, W. Dejnirattisai, P. Supasa, A. J. Mentzer, B. Wang, J. B. Case, Y. Zhao, D. T. Skelly, R. E. Chen, S. A. Johnson, T. G. Ritter, C. Mason, T. Malik, N. Temperton, N. G. Paterson, M. A. Williams, D. R. Hall, D. K. Clare, A. Howe, P. J. R. Goulder, E. E. Fry, M. S. Diamond, J. Mongkolsapaya, J. Ren, D. I. Stuart, G. R. Screaton, The antibody response to SARS-CoV-2 Beta underscores the antigenic distance to other variants. Cell Host \& Microbe (2021), , doi:10.1016/j.chom.2021.11.013.

45. X. Shen, H. Tang, C. McDanal, K. Wagh, W. Fischer, J. Theiler, H. Yoon, D. Li, B. F. Haynes, K. O. Sanders, S. Gnanakaran, N. Hengartner, R. Pajon, G. Smith, G. M. Glenn, B. Korber, D. C. Montefiori, SARS-CoV-2 variant B.1.1.7 is susceptible to neutralizing antibodies elicited by ancestral spike vaccines. Cell Host Microbe. 29, 529-539.e3 (2021).

46. A. C. Cohen, Progressively Censored Samples in Life Testing. Technometrics. 5, 327-339 (1963).

47. J. J. P. Nauta, Eliminating bias in the estimation of the geometric mean of HI titres. Biologicals. 34, 183-186 (2006).

48. J. Tobin, Estimation of Relationships for Limited Dependent Variables. Econometrica. 26, 24-36 (1958).

49. B. D. Ripley, The R project in statistical computing. MSOR connect. 1, 23-25 (2001).

50. S. Wilks, meantiter, (available at https://github.com/shwilks/meantiter).

51. R interface to CmdStan, (available at https://mc-stan.org/cmdstanr).

52. Stan. stan-dev.github.io, (available at https://mc-stan.org).

53. J. Kruskal, M. Wish, Multidimensional Scaling (1978), , doi:10.4135/9781412985130.

54. A. Lapedes, R. Farber, The geometry of shape space: application to influenza. J. Theor. Biol. 212, 57-69 (2001).

55. R. J. Garten, C. T. Davis, C. A. Russell, B. Shu, S. Lindstrom, A. Balish, W. M. Sessions, X. Xu, E. Skepner, V. Deyde, M. Okomo-Adhiambo, L. Gubareva, J. Barnes, C. B. Smith, S. L. Emery, M. J. Hillman, P. Rivailler, J. Smagala, M. de Graaf, D. F. Burke, R. A. M. Fouchier, C. Pappas, C. M. Alpuche-Aranda, H. López-Gatell, H. Olivera, I. López, C. A. Myers, D. Faix, P. J. Blair, C. Yu, K. M. Keene, P. D. Dotson Jr, D. Boxrud, A. R. Sambol, S. H. Abid, K. St George, T. Bannerman, A. L. Moore, D. J. Stringer, P. Blevins, G. J. 
bioRxiv preprint doi: https://doi.org/10.1101/2022.01.28.477987; this version posted January $28,2022$. The copyright holder for this preprint (which was not certified by peer review) is the author/funder, who has granted bioRxiv a license to display the preprint in perpetuity. It is made available under aCC-BY-NC-ND 4.0 International license.

Demmler-Harrison, M. Ginsberg, P. Kriner, S. Waterman, S. Smole, H. F. Guevara, E. A. Belongia, P. A. Clark, S. T. Beatrice, R. Donis, J. Katz, L. Finelli, C. B. Bridges, M. Shaw, D. B. Jernigan, T. M. Uyeki, D. J. Smith, A. I. Klimov, N. J. Cox, Antigenic and genetic characteristics of swine-origin 2009 A(H1N1) influenza viruses circulating in humans. Science. 325, 197-201 (2009).

56. D. Thi Nguyen, S. S. Shepard, D. F. Burke, J. Jones, S. Thor, L. Van Nguyen, T. D. Nguyen, A. Balish, D. N. Hoang, T. L. To, M. Iqbal, D. E. Wentworth, E. Spackman, H. R. van Doorn, C. T. Davis, J. E. Bryant, Antigenic characterization of highly pathogenic avian influenza $A(H 5 N 1)$ viruses with chicken and ferret antisera reveals clade-dependent variation in hemagglutination inhibition profiles. Emerg. Microbes Infect. 7, 100 (2018).

57. C. Zhu, R. H. Byrd, P. Lu, J. Nocedal, Algorithm 778: L-BFGS-B: Fortran subroutines for large-scale bound-constrained optimization. ACM Trans. Math. Softw. 23, 550-560 (1997).

58. Racmacs, (available at https://acorg.github.io/Racmacs/).

59. S. H. Wilks, thesis, University of Cambridge (2018).

60. A. M. Lesk, Introduction to bioinformatics, 1--314 Oxford University Press (2002).

\begin{abstract}
Acknowledgements:
We thank Amanda Eaton, Elizabeth Domin, Sarah Hiles, Jin Tong, Leihua Liu, Kellen Lund, Jiayu Chen, Kendall Bradley, and Wenhong Feng, Duke University, for immunological analysis. We thank our collaborators on sample collection and coordination: Samantha Kaweski, Citlali Marquez, BC Centre for Disease Control; The Community Surveillance for Infection Team, Epidemiology Task Force, COVID-19 Response (Melissa Rolfes, and Ashton Dixon), and the Genomics and Discovery Team, Respiratory Virus Branch DVD, NCIRD from Centers for Disease Control and Prevention; The Coronavirus Household Evaluation and Respiratory Testing (C-HEaRT) Cohort Columbia University team (Priyam Thind, Maria Castro, Franklin Sosa, and Liqun Wang) and Abt Associates, Inc. team (Jazmin Duque, Zuha Jeddy, Kim Altunkaynak, Michael Duckworth, and Utsav Kattel); CoVPN- COVID-19 Prevention Network; Natural history of SARS-CoV-2 and Influenza in Peru Study Team; Christina Barkauskas, Shayna Wolery, and Ibtehaj Naqvi, Duke University Medical Center, the Personalized Virology Initiative at the Icahn School of Medicine at Mount Sinai (Deena Altman, Maria C Bermúdez-González, Miti Saksena, Komal Srivastava, Charles Gleason, Giulio Kleiner, Ania Wajnberg) and the Mount Sinai Pathogen Surveillance Program (Ana Silvia Gonzalez-Reiche, Emilia Mia Sordillo, Alberto Paniz-Mondolfi); John Beigel and Paul C. Roberts from Division of Microbiology and Infectious Diseases, National Institute of Allergy and Infectious Diseases, National Institutes of Health, Bethesda, MD, USA.
\end{abstract}

\title{
Funding:
}

SHW, ST, EBL, AN, RAMF, TCJ, DJS: NIH Centers of Excellence for Influenza Research and Surveillance (CEIRS, contract \#HHSN272201400008C) and Centers of Excellence for Influenza Research and Response (CEIRR, contract \#75N93021C00014).

XS, DCM, CM, HT, LD: SARS-CoV-2 Assessment of Viral Evolution (SAVE) Program (Contract \#75N93019C00050 Opt 18A \& 18B).

BM, TCJ, CD: Funded by the German Federal Ministry of Education and Research (Bundesministerium für Bildung und Forschung) through project DZIF (8040701710 and 8064701703).

HvB, VS, FK: NIAID Centers of Excellence for Influenza Research and Response (CEIRR) contract 75N93021C00014, SAVE option 12A, the NIAID Collaborative Influenza Vaccine Innovation Centers (CIVIC) contract 75N93019C00051.

EBL is funded by a Gates Cambridge Scholarship.

RP: Moderna, Inc. Also supported by the Office of the Assistant Secretary for Preparedness and Response, Biomedical Advanced Research and Development Authority (contract 75A50120C00034) and by the National Institute of Allergy and Infectious Diseases (NIAID).

YK: Center for Research on Influenza Pathogenesis and Transmission (CRIPT) (75N93021C00014), and the Japan Program for Infectious Diseases Research and Infrastructure (JP21wm0125002) from the Japan Agency for Medical Research and Development (AMED).

\section{Author contributions:}

Conceptualization: SHW, BM, XS, DCM, DJS

Methodology: SHW, DJS

Software: SHW, TCJ

Validation: SHW, BM, XS, ST, EBL, AN, DCM, DJS

Formal analysis: SHW, BM, XS, ST, EBL, AN

Investigation: SHW, BM, XS, ST, EBL, AN, DCM, DJS 
Resources: XS, MAC, JNC, MBD, TND, CD, RAMF, PJG, PJH, AJ, YK, FK, RP, VS, MS, HvB, RW, DCM, DJS

Data curation: SHW, BM, XS

Writing - Original Draft: SHW, BM, DJS

Writing - Review and Editing: All

Visualization: SHW, BM, ST, AN, EBL

Supervision: DCM, DJS

\section{Competing interests:}

The authors declare no competing interests.

\section{Data and materials availability:}

All data, code and materials will be made available on request.

\section{Supplementary Materials}

Materials and Methods

Table S1-S2

Fig S1-S31 
bioRxiv preprint doi: https://doi.org/10.1101/2022.01.28.477987; this version posted January 28, 2022. The copyright holder for this preprint (which was not certified by peer review) is the author/funder, who has granted bioRxiv a license to display the preprint in perpetuity. It is made available under aCC-BY-NC-ND 4.0 International license.

\section{Figures and figure legends}
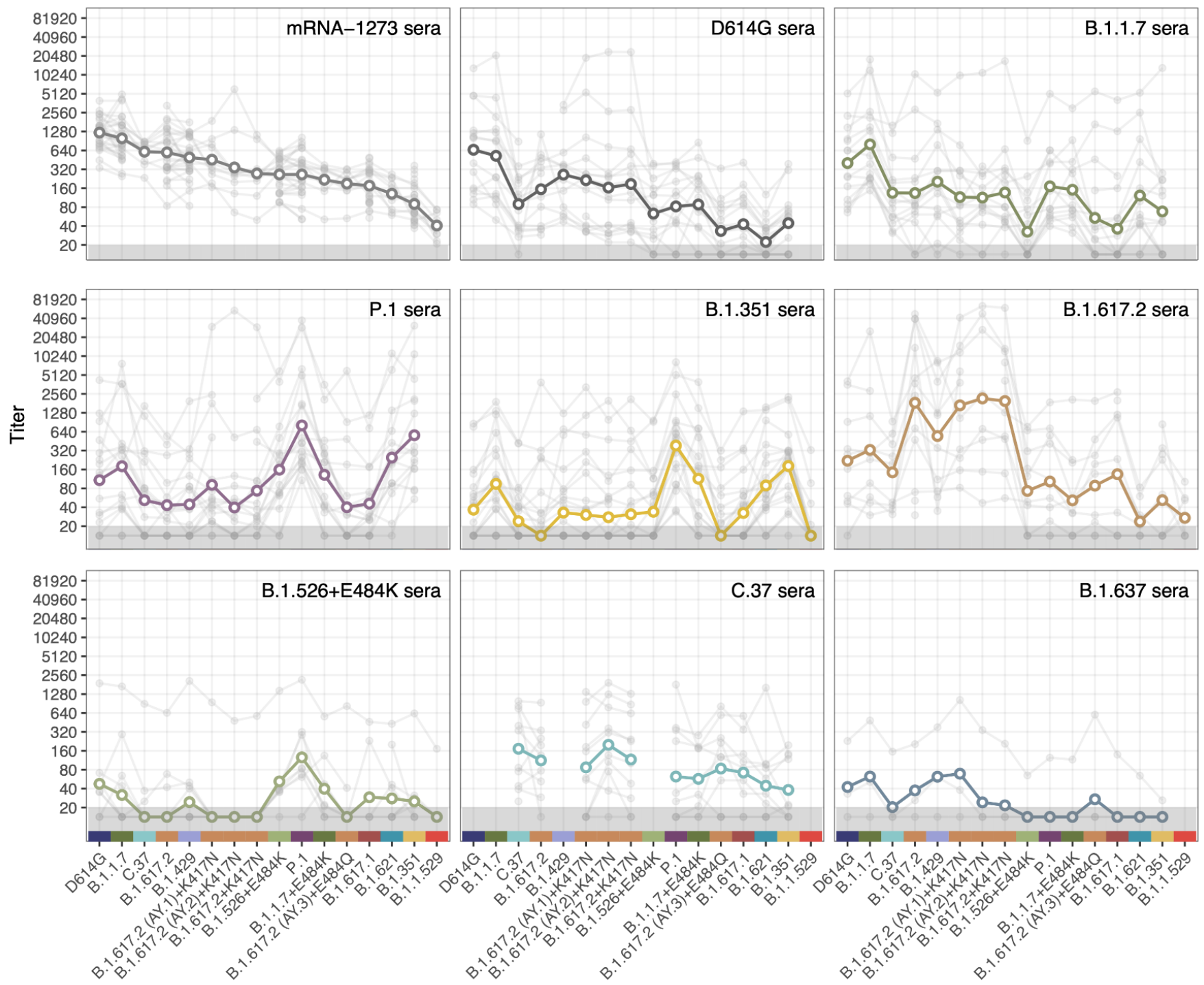

Fig. 1: Neutralization of lentivirus pseudotypes encoding different SARS-CoV-2 spike proteins by patient sera collected after vaccination or infection with different variants. Variants are ordered according to geometric mean titer (GMT) in mRNA-1273 sera (top left), which allows for direct comparison in a column. Bold lines with empty circles show the GMTs, fainter individual lines and solid points show individual serum titers. Points in the gray region at the bottom of the plots show titers and GMTs that fell below the detection threshold of 20. Titer box plots and line plots accounting for individual effects are shown in figs. S1 and S2 respectively. GMTs for data including non-detectable titers is calculated as described in Materials and Methods, 'Titer Analyses' section. 
bioRxiv preprint doi: https://doi.org/10.1101/2022.01.28.477987; this version posted January 28, 2022. The copyright holder for this preprint (which was not certified by peer review) is the author/funder, who has granted bioRxiv a license to display the preprint in perpetuity. It is made available under aCC-BY-NC-ND 4.0 International license.

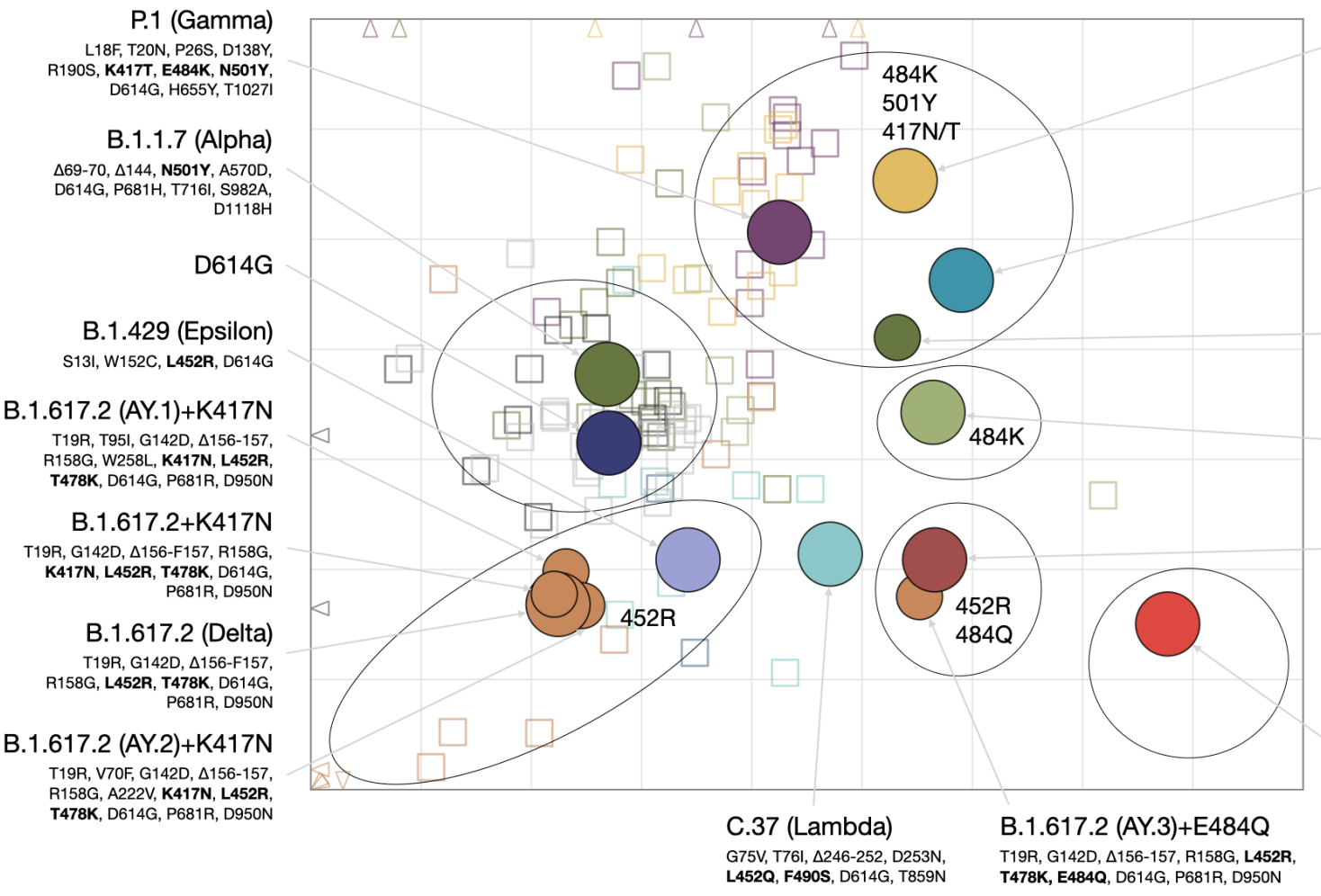

B.1.351 (Beta)

L18F, D80A, D215G, $\triangle 242-244$, R246I, K417N, E484K, N501Y D614G, A701V

\section{B.1.621 (Mu)}

T95I, insert143T, Y144S, Y145N, R346K, E484K, N501Y, D614G,

\section{B.1.1.7+E484K}

$\triangle 69-70, \Delta 144$, E484K, N501Y, S982A, D1118H

B.1.526+E484K (lota) L5F, T951, D253G, E484K, D614G, A701V

\section{B.1.617.1 (Kappa)}

G142D, E154K, L452R, E484Q, D614G, P681R, Q1071H

B.1.1.529 (Omicron) A67V, $\triangle 69-70$, T951, G142D, $\Delta 143-145, N 2111, \Delta 212$, S373P, S375F, K417N, N440K, G446S, S477NN, T478K, E484A, Q493R, G496S, Q498R, N501Y, Y505H, T547K, D614G, H655Y N679K, P681H, N764K, D796Y, N856K, Q954H, N969K, L981F

Fig. 2: Antigenic map of SARS-CoV-2 variants and selected substitutions. Variants are shown as circles, sera as squares. Variants with additional substitutions from a root variant are denoted by smaller circles, in the color of their root variant. The $x$ and $y$-axes both represent antigenic distance, with one grid square corresponding to one two-fold serum dilution in the neutralization assay. Therefore, two grid squares correspond to a four-fold dilution, three to an eight-fold dilution and so on. The orientation of the map within the $\mathrm{x}$ and $\mathrm{y}$ axes is free, as only the relative distances between variants and sera can be inferred. Triangular arrowheads at the edge of the bounding box point in the direction of the sera that would be shown outside of the plot limits. Six antigenic areas are delimited by ovals: 1) Left-middle: D614G convalescent and vaccine sera, D614G and B.1.1.7 variants. 2) Top-right: B.1.351 and P.1 sera, P.1, B.1.351, B.1.621, B.1.1.7+E484K variants. 3) Middle-right: B.1.526+E484K variant. 4) Bottom-left: B.1.617.2 sera, B.1.617.2, B.1.617.2+K417N, B.1.429 variants. 5) Bottom-right: B.1.617.1 and B.1.617.2+E484Q variants. 6) Furthest-right: B.1.1.529 variant. A non-zoomed version of this map is shown in fig. S20. 
bioRxiv preprint doi: https://doi.org/10.1101/2022.01.28.477987; this version posted January 28, 2022. The copyright holder for this preprint (which was not certified by peer review) is the author/funder, who has granted bioRxiv a license to display the preprint in perpetuity. It is made available under aCC-BY-NC-ND 4.0 International license.
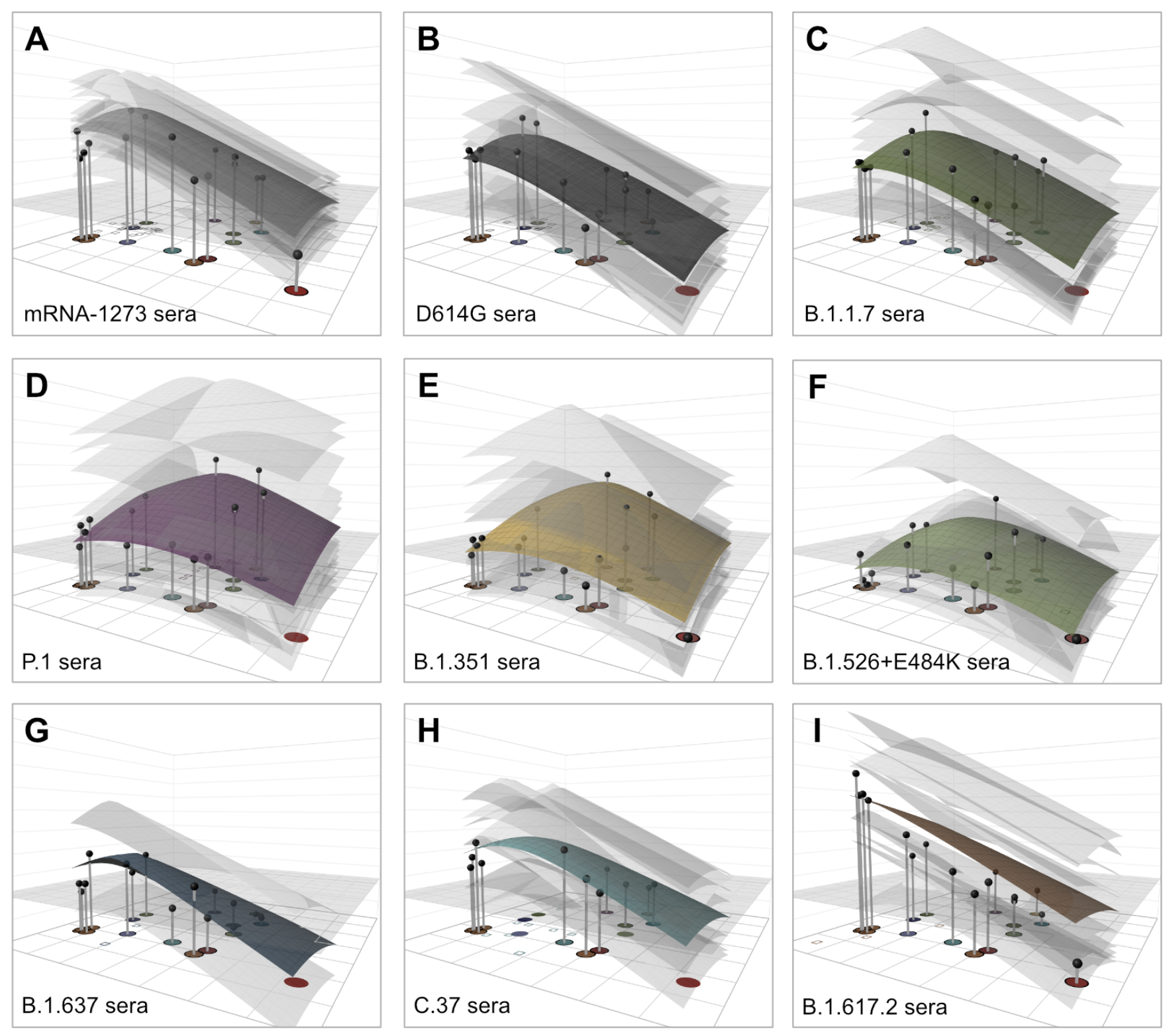

Fig. 3: Antibody landscapes for each serum group. Colored surfaces show the GMT antibody landscapes for the different serum groups, light gray surfaces show the landscapes for each individual serum. Gray impulses show the height of the GMT for a specific variant, after accounting for individual effects as described in Materials and Methods (which would otherwise bias the GMT for variants not titrated against all sera). The base $x-y$ plane corresponds to the antigenic map shown in Fig. 2. The vertical z-axis in each plot corresponds to the titer on the $\log _{2}$ scale, each two-fold increment is marked, starting from a titer of 20 , one unit above the map surface. The gray horizontal plane indicates the height of a titer of 50 , as a reference for judging the landscapes against various estimates of neutralizing antibody correlates of protection. Additional visualizations of predicted vs fitted titers are shown in fig. S21. 
bioRxiv preprint doi: https://doi.org/10.1101/2022.01.28.477987; this version posted January $28,2022$. The copyright holder for this preprint (which was not certified by peer review) is the author/funder, who has granted bioRxiv a license to display the preprint in perpetuity. It is made available under aCC-BY-NC-ND 4.0 International license.
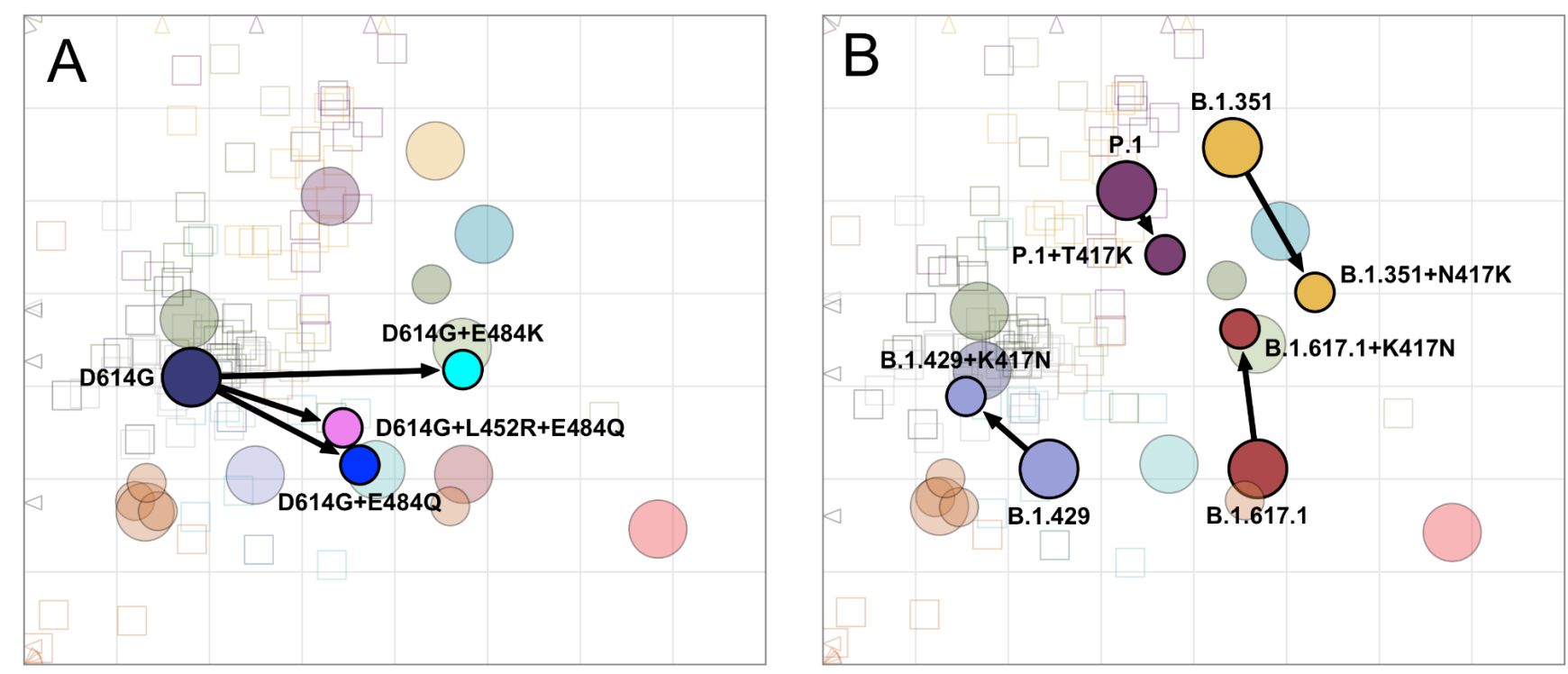

Fig. 4: Antigenic maps including laboratory made variants with substitutions at positions 484, 452, and 417. The same antigenic map as shown in Fig. 2 but additionally showing laboratory made mutants. A) Variants with substitutions E484K, $\mathrm{E} 484 \mathrm{Q}, \mathrm{L} 452 \mathrm{R}+\mathrm{E} 484 \mathrm{~K}$ in the background of D614G; D614G+L452R is not shown since it was titrated against only D614G sera and so its position would not be well triangulated in the map. B) Variants with the T/N417K substitution in the background of P.1 and B.1.351 respectively, and $\mathrm{K} 417 \mathrm{~N}$ in the background of B.1.429 and B.1.617.1. Arrows point from the antigenic position of the root virus to that of the laboratory-generated variant. 
bioRxiv preprint doi: https://doi.org/10.1101/2022.01.28.477987; this version posted January 28, 2022. The copyright holder for this preprint (which was not certified by peer review) is the author/funder, who has granted bioRxiv a license to display the preprint in perpetuity. It is made available under aCC-BY-NC-ND 4.0 International license.


Fig. 5: Effect of substitutions at positions 484 and 417 on D614G and B.1.351 serum reactivity. Titer plots for each D614G and B.1.351 serum against different variants, with serum identifier on the $x$-axis and titer on the $y$-axis. A, B) D614G, D614G+E484K (laboratory made), and B.1.526+E484K variants. C, D) B.1.351, B.1.351+N417K (laboratory made), and B.1.526+E484K variants. Sera are ordered by GMT of the three variants they are plotted against. Laboratory made variants and natural variants are shown as dashed and continuous lines, respectively. Points in the gray region at the bottom of the plots show titers that fell below the detection threshold of 20 . 